\title{
Modulation of hippocampal long-term potentiation and long-term depression by corticosteroid receptor activation
}

\author{
D. STEVEN KERR, ANN M. HUGGETT, and WICKLIFFE C. ABRAHAM \\ University of Otago, Dunedin, New Zealand
}

\begin{abstract}
Long-term potentiation (LTP) and long-term depression (LTD) are lasting changes in synaptic efficacy which may underlie memory and learning processes. Hippocampal LTP has been shown to vary inversely with the degree of stress or adrenal activity, and adrenal corticosteroids (CORT) have been strongly implicated in this process. The present in vitro study was undertaken to further examine the role of glucocorticoids in LTP, and to extend this analysis to heterosynaptic LTD. Animals were injected twice daily (s.c.) for 2 days prior to sacrifice with either the corticosteroid biosynthesis inhibitor metyrapone $(200 \mathrm{mg} / \mathrm{kg} /$ day $)$ or CORT $(20 \mathrm{mg} / \mathrm{kg} /$ day $)$. Noninjected and saline-injected controls were also examined. CA1 population spike amplitudes and field EPSP slopes were assessed in response to activation of two separate stratum radiatum inputs. One input received tetanic stimulation and both inputs were monitored for 30 min following tetanization to determine long-term changes in synaptic efficacy (homosynaptic LTP of tetanized synapses; heterosynaptic LTD of nontetanized synapses). Animals exhibiting low and high serum CORT titers exhibited significantly less LTP and LTD than did animals exhibiting moderate levels of CORT. In addition, in vitro perfusion of RU-28362, a Type II glucocorticoid receptor agonist, markedly reduced both LTP and LTD. There was no correlation between serum CORT and serum glucose titers, nor was there any correlation between serum glucose and either LTP or LTD. These results are consistent with recent reports of an inverted-U function for CORT levels versus primedburst LTP (Bennett, Diamond, Fleshner, \& Rose, 1991; Diamond, Bennett, Fleshner, \& Rose, 1992) and further demonstrate that manipulation of corticosterone in adrenal-intact animals affects LTP and LTD in a similar fashion.
\end{abstract}

It is well established that the hippocampus and related brain structures are rich in specific corticosteroid receptors (CSRs) (Fuxe et al., 1985; McEwen, Wallach, \& Magnus, 1974; McEwen, Weiss, \& Schwartz, 1969; Reul $\&$ de Kloet, 1986). At least two types of cytosolic CSRs have been differentiated on the basis of their steroid binding characteristics: Type I (MR, mineralocorticoid/corticosteroid) and Type II (GR, glucocorticoid) receptors. In the rat, Type I receptors exhibit the higher affinity for corticosterone (CORT, the naturally occurring endogenous glucocorticoid in the rodent) and are probably tonically activated even under conditions of low plasma titers of CORT. In contrast, Type II receptors exhibit a much lower affinity for CORT and, as such, appear to be activated mostly under conditions of high circulating CORT (e.g., diurnal peaks, stress; Dallman et al., 1987; de Kloet,

We gratefully acknowledge the excellent technical assistance of B. Dingwall, R. Phillips, and W, van der Vliet. We thank B. Christie for reviewing this manuscript. We also thank Roussel-Uclaf, Romainville, France for kindly providing us with RU-28362. This study was supported by the New Zealand Health Research Council and the Human Frontier Science Program. D. S. K. was supported by a New Zealand Health Research Council Postdoctoral Fellowship. Correspondence should be sent to D. S. Kerr, Department of Psychology, University of Otago, P. O. Box 56, Dunedin, New Zealand.
Ratka, Reul, Sutanto, \& van Eekelen, 1987; Reul, van den Bosch, \& de Kloet, 1987). It appears that the Type I and Type II receptors are components of two functionally distinct systems that mediate differing metabolic and physiological responses within the hippocampus (see Joels \& de Kloet, 1992a, 1992b; Schlatter \& Dokas, 1989).

Because of the widely varying actions of corticosteroids on hippocampal function, and because of the prominent role of the hippocampus in memory and learning processes, a number of studies have been carried out in recent years to address the question of modulation of longterm potentiation (LTP) under varying conditions of stress or adrenal activity. Early studies demonstrated that LTP in the dentate gyrus is significantly diminished following adrenalectomy but can be restored by in vivo or in vitro administration of CORT (Dana et al., 1982; Dana \& Martinez, 1984; Nowicky, Vardaris, \& Teyler, 1983). In contrast, a number of investigators have demonstrated a significant impairment of LTP among animals exposed to CORT (Pavlides, Watanabe, \& McEwen, 1993) or to a variety of stressful conditions, in comparison with unstressed controls (Diamond, Bennett, Stevens, Wilson, \& Rose, 1990; Foy, Stanton, Levine, \& Thompson, 1987; Shors, Seib, Levine, \& Thompson, 1989). Similarly, several studies have indicated that surgical adrenalectomy (ADX) can prevent stress-related reductions in LTP (Di- 
amond, Bennett, Engstrom, Fleshner, \& Rose, 1989; Shors, Levine, \& Thompson, 1988).

Recently, in vivo studies of hippocampal region CA1 (Bennett, Diamond, Fleshner, \& Rose, 1991; Diamond, Bennet, Fleshner, \& Rose, 1992) have shown that the magnitude of primed-burst long-term potentiation (PBLTP) varies with serum CORT levels according to an inverted-U shaped function, such that very low and very high CORT levels are associated with diminished PBLTP, whereas midrange serum CORT titers (presumably sufficient to activate the Type I receptor only) are associated with a robust expression of PB-LTP. A recent report by Pavlides, Watanabe, Margarinos, and McEwen (1992) has indicated a strikingly similar pattern of LTP modulation by CORT in the dentate gyrus. In the latter study, surgically adrenalectomized (ADX) rats exhibited robust LTP in vivo following the administration of the Type I CSR agonist aldosterone, while exhibiting diminished LTP following administration of the Type II CSR agonist RU-28362 or vehicle (Pavlides et al., 1992).

Although LTP has been reported to vary with serum CORT titers, there is still little actual evidence that glucocorticoids (alone) are involved in the various reported effects. That is, many of the studies have utilized surgical ADX or stress (or both) to produce variations in serum CORT, without providing sufficient control of ADX-and stress-induced variations in adrenal catecholamines, adrenal opioids, and ACTH. The latter factors have also been implicated in the modulation of LTP (Gold, Delanoy, \& Merrin, 1984; Shors, Levine, \& Thompson, 1990a, 1990b) and memory and learning processes (de Wied, 1989; Gold $\&$ van Buskirk, 1975, 1976), and they should be considered as possible experimental confounds (or cofactors; $c f$. Axelrod \& Reisine, 1984) in at least some of the glucocorticoid studies cited above.

In addition, most of the conclusions to date regarding LTP have been based on extracellular measures of population spike amplitude only, and more direct measures of altered synaptic efficacy by assessment of the field EPSP have been largely neglected. Moreover, although a homosynaptic primed-burst long-term depression (PB-LTD) was recently observed in very high CORT animals (Diamond, Bennett, et al., 1992), neither this nor other forms of synaptic plasticity such as heterosynaptic LTD have been systematically examined. Thus, a number of questions regarding the modulation of LTP and LTD by stress or ADX remain unresolved.

In the present experiments, adrenal-intact adult rats were administered either the corticosteroid biosynthesis inhibitor metyrapone or corticosterone as a means of directly manipulating serum CORT levels in vivo. LTP and heterosynaptic LTD were then assessed in vitro, utilizing measures of both the population spike and the field EPSP to assess changes in synaptic efficacy and gross hippocampal function (preliminary results of this study have appeared in abstract form: Kerr, Huggett, \& Abra- ham, 1993). Consistent with recent reports (Bennett et al., 1991; Diamond, Bennett, et al., 1992; Pavlides et al., 1992), our results indicate a strong inverted-U shaped relationship between serum CORT level and the magnitude of LTP. In addition, modulation of heterosynaptic LTD also conforms to an inverted-U shaped function. For both LTP and LTD, alterations in the slope of the field EPSP lend support to the hypothesis that the changes observed are due to direct effects on synaptic efficacy, as opposed to modulation of local inhibition or neuronal excitability.

\section{METHOD}

Hippocampal slices (400- $\mu \mathrm{m}$ transverse sections) were prepared from 3- to 4-month-old, male Sprague-Dawley rats and were maintained fully submerged in a standard brain slice chamber. The slices were constantly perfused with an artificial cerebrospinal fluid consisting of $124.0 \mathrm{mM} \mathrm{NaCl}, 3.2 \mathrm{mM} \mathrm{KCl}, 1.25 \mathrm{mM} \mathrm{NaH}_{2} \mathrm{PO}_{4}$, $26.0 \mathrm{mM} \mathrm{NaHCO}, 2.0 \mathrm{mM} \mathrm{CaCl}_{2}, 2.0 \mathrm{mM} \mathrm{MgCl}, 10.0 \mathrm{mM}$ glucose, and $0.5 \mu \mathrm{M}$ picrotoxin $\left(33^{\circ}-34^{\circ} \mathrm{C}\right.$, saturated with $95 \% \mathrm{O}_{2}$ ' $5 \% \mathrm{CO}_{2}$ ). Picrotoxin has been shown to enhance the induction of LTD in the hippocampus (Abraham \& Wickens, 1991; Kerr \& Abraham, 1993) and was included here for that reason. In order to reduce potential hyperexcitability and the spread of seizure-like activity during tetanization, region $\mathrm{CA} 3$ was removed by a manual knife cut during hippocampal dissection (Figure 1). This procedure, previously employed by Abraham and Wickens (1991) among others, does not adversely affect the evoked responses normally observed in vitro.

CA1 field potentials, recorded from stratum pyramidale and stratum radiatum, were assessed in response to monosynaptic activation of separate Schaffer collateral/commissural inputs. Monopolar electrical microstimulation with $25-\mu \mathrm{m}$ teflon-coated steel wires, applied on opposite sides of the recording site (see Figure 1), yielded robust synaptic responses. These microstimulation procedures have been shown to reliably yield greater than $95 \%$ separation of the activated converging afferent inputs, as evidenced by summation tests of the individual slopes of the fiber volleys (Kerr \& Abraham, 1993). One input served as the conditioning pathway and received "theta-burst" tetanic stimulation consisting of eight trains (2-sec duration) of brief, $100-\mathrm{Hz}$ bursts (five biphasic pulses per burst, $200-\mu \mathrm{sec}$ per pulse) delivered $200 \mathrm{msec}$ apart, sufficient to produce homosynaptic LTP; the other (test) pathway received no concurrent stimulation during the conditioning procedure.

Baseline potentials were monitored for $15 \mathrm{~min}$ prior to conditioning stimulation, and recordings continued for at least $30 \mathrm{~min}$ following stimulation procedures. Initial stimulation intensities were adjusted to yield moderate (1- to $1.5-\mathrm{mV}$ population spike) responses (Figure 3). Population spike amplitudes (in millivolts, defined as the height of the spike from peak negativity to a point of intersection with a tangent line along the rising face of the positive wave; see Figure 1 legend) and field EPSP initial slopes (millivolts/millisecond) were measured off line, using ASYST-based software written in our lab, and were expressed as percent change from baseline values. Slices not exhibiting stable baseline potentials for at least $10 \mathrm{~min}$ prior to conditioning were discarded from the study. Slices were not discarded for reasons of failure to exhibit LTP following conditioning. Student $t$ tests and two-way analyses of variance (ANOVAs) were performed with repeated measures designs for the $10-, 15-$, and 30-min posttetanization time points in order to assess group differences following the various treatments. Earlier time points were excluded from these analyses in order to avoid con- 

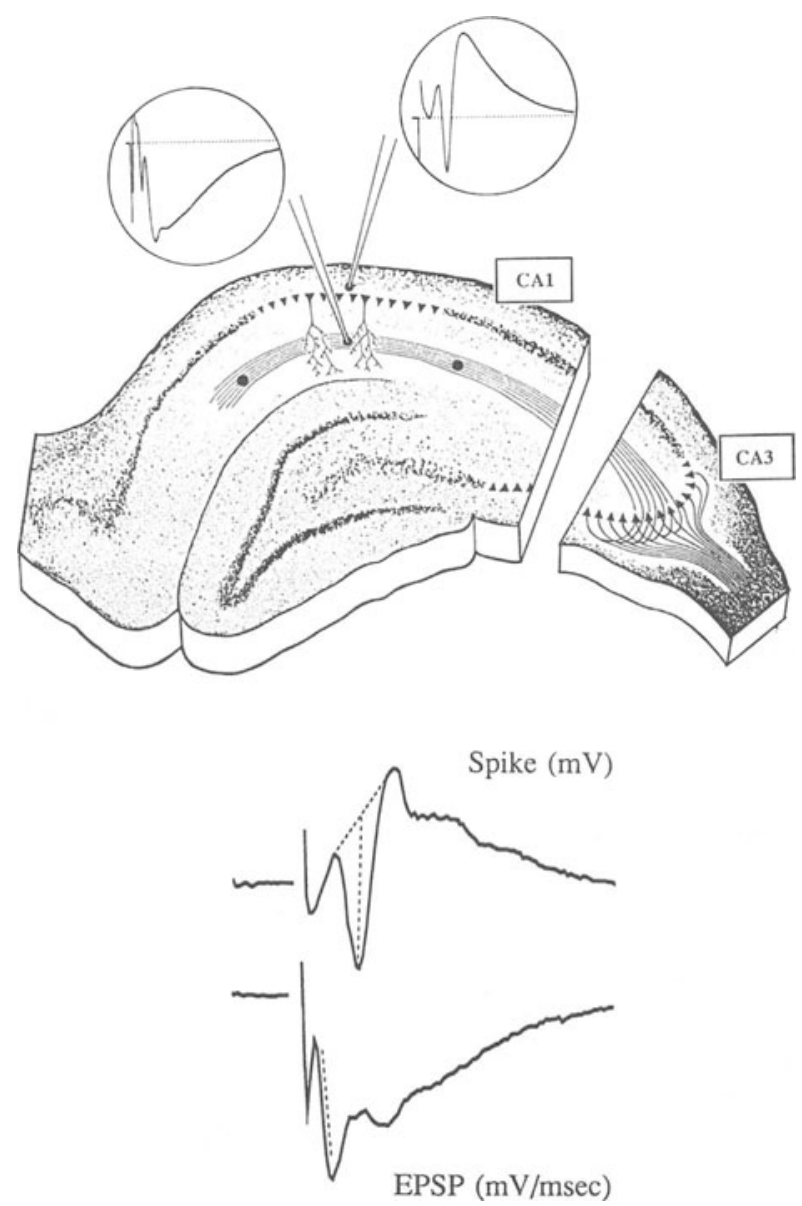

Figure 1. Top: Schematic diagram of hippocampal slice. Area CA3 was removed during dissection to reduce hyperexcitability. Extracellular recording electrodes were positioned in stratum pyramidale and stratum radiatum of area CA1; insets show typical evoked responses observed at these sites. Stimulation sites are indicated by the black dots superimposed over the Schaffer collateratcommissural fibers in stratum radiatum, on opposite sides of the recording sites. Bottom: Representative waveforms (population spike above, field EPSP below) illustrating methods of waveform analysis. Spike amplitudes (millivolts) were defined as the height of a line extending from the peak negativity to a tangent across the rising face of the positive wave (vertical dashed line). Field EPSP slopes (millivolts/ millisecond) were defined as the rate of change along the most linear portion of the negative-going face of the EPSP.

tamination of the long-term changes with the more dramatic shortterm depression normally arising after strong tetanization. Statistical significance was determined at a confidence level of $p<.05$.

\section{Blood Collection, CORT, and Glucose Assays}

Following anesthetization (ether vapor) and rapid decapitation, trunk bloods were collected from each animal. Samples were maintained on ice and allowed to clot for approximately $3 \mathrm{~h}$; then they were centrifuged at $800 \times \mathrm{G}$ for $10 \mathrm{~min}$ to yield whole-cell and platelet-free serum. Serum corticosterone was assayed with the use of a commercially prepared radioimmunoassay (RIA) highly specific for rat corticosterone (Coat-a-Count RIA Kit; Diagnostic Products Corp., Los Angeles, CA). Minimum detectable levels for this assay are less than $1 \mu \mathrm{g} / \mathrm{dl}$, and nonspecific binding is negligible
( $\leq 0.6 \%$ ). Under our assay conditions, parallelism tests indicated no interference by metyrapone or any other endogenous serum components, and although not assessed during the present study, intraand interassay coefficients of variation for this assay generally vary between $4.0 \%-4.3 \%$ and $4.8 \%-5.8 \%$, respectively.

Because CORT can affect peripheral glucose titers, and because brain glucose levels have been shown to correlate with certain types of learning (Gold, 1986; Lee, Graham, \& Gold, 1988), we also assessed serum glucose levels in all animals used in Experiment 1 of the present study. Glucose titers were determined with the use of an automatic analyzer and a commercially prepared diagnostic kit (Glucose HK kit, Roche Inc.) utilizing a standard two-step enzymatic reaction (hexokinase and glucose-6-phosphate dehydrogenase) yielding NADH quantified by measurement of absorbance at $340 \mathrm{~nm}$.

\section{Experiment 1}

Twenty-four rats (average body weight, $328 \mathrm{~g}$; range, $310-365 \mathrm{~g}$ ) were divided into four groups: noninjected intact controls (INT, $n=8$ ), saline-injected controls (SAL, $n=6$ ), and two groups consisting of animals injected with either the corticosteroid biosynthesis inhibitor metyrapone (Sigma Chemical Co., St. Louis; MET, $200 \mathrm{mg} / \mathrm{kg} /$ day, s.c., $n=5$ ) or corticosterone (Sigma Chemical Co.; CORT, $20 \mathrm{mg} / \mathrm{kg} /$ day, s.c., $n=5$ ). All animals were weighed and rehoused in isolation. Experimental subjects and saline-injected controls were each injected twice daily (two half-doses), once at 9:00 a.m. and again at 4:00 p.m. for 2 days prior to sacrifice, and once again on the morning of Day 3 , approximately $2 \mathrm{~h}$ prior to sacrifice. This method was adopted to ensure slow release, yielding relatively constant levels of metyrapone and CORT throughout the treatment period and to ensure that any CORT-related genomic events were at equilibrium well before the in vitro studies. These dosages are within ranges previously reported to produce either relatively CORT-free, pharmacologically adrenalectomized animals (cf. Murison, Overmeier, Hellhammer, \& Carmona, 1989; Stein \& Sapolsky, 1988), or stress-equivalent high-CORT animals (cf. Sapolsky, Krey, \& McEwen, 1985) respectively. Noninjected and saline-injected animals were included to control for stress effects due to handling and rehousing.

\section{Experiment 2}

To assess possible direct effects of metyrapone itself (i.e., effects on synaptic plasticity not related to inhibition of CORT synthesis), an additional group of animals was injected with both metyrapone and CORT (MET + CORT, $n=6$, dosages as above). In addition, to directly assess the role of the Type II glucocorticoid receptor in the modulation of LTP and LTD, a highly specific Type II receptor agonist, RU-28362, was administered to slices by constant in vitro perfusion (10 $\mu \mathrm{M}$ in artificial cerebrospinal fluid). These experiments were carried out in metyrapone-injected animals (MET $+\mathrm{RU}, n=2$ ) as well as noninjected controls (INT $+\mathrm{RU}, n=4$ ).

\section{RESULTS}

\section{Serum CORT and Glucose Titers}

Radioimmunoassay of serum CORT revealed that it differed for the four groups assessed in Experiment 1 (Figure $2 \mathrm{~A}$; final $n \mathrm{~s}$ indicated for each group below.). Salineinjected and noninjected controls exhibited low to moderate levels of serum CORT, respectively (mean $\mu \mathrm{g} / \mathrm{dl} \pm$ SEM: SAL, 3.8 $\pm 0.7, n=6$; INT, $7.1 \pm 3.8, n=5$ ). CORT-injected animals exhibited elevated serum CORT titers $(25.4+9.3, n=4)$ consistent with those values observed in acutely or chronically stressed animals (Eldridge, Brodish, Klute, \& Landfield, 1989; Foy et al., 

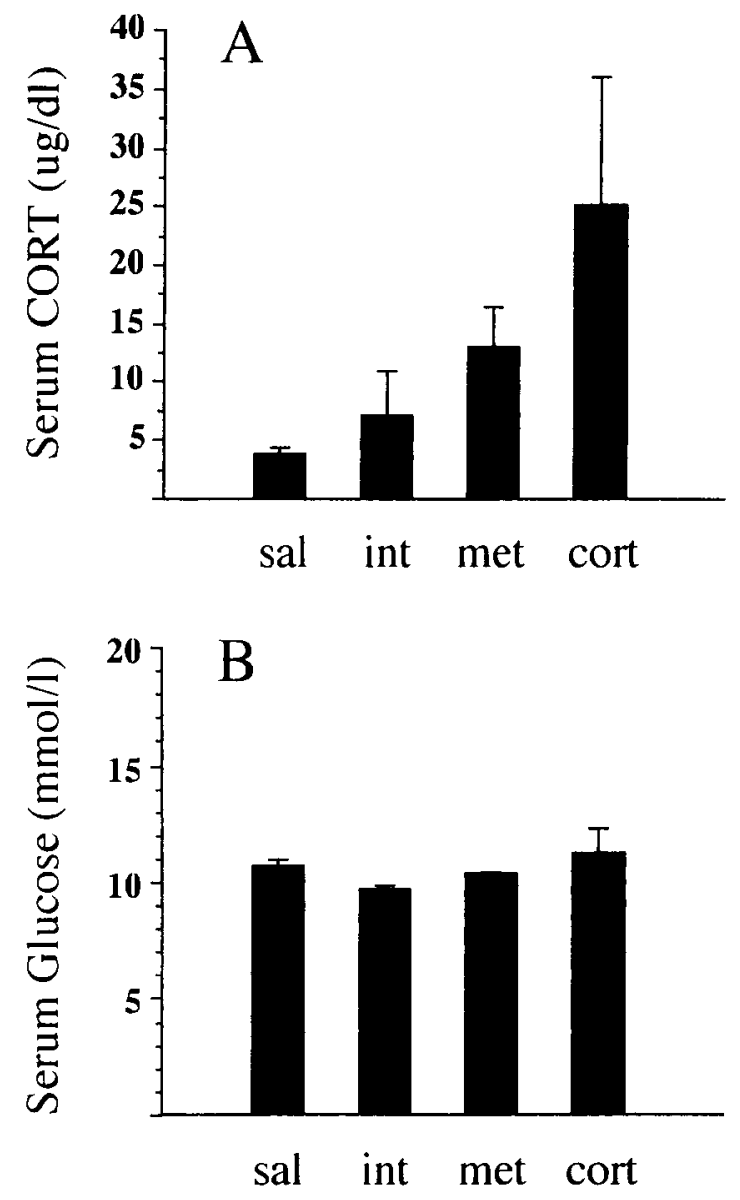

Figure 2. (A) Serum corticosterone (mean $\mu \mathrm{g} / \mathrm{dl} \pm S E M$ ) and (B) serum glucose (mean mmoles/l $\pm S E M$ ) levels for the four groups in Experiment 1. Final as for each group are as follows: $S A L, n=6$; INT, $n=5$; MET, $n=5$; CORT, $n=4$.

1987; Odio \& Brodish, 1989). In addition, three MET + CORT animals (Experiment 2) for which bloods were available exhibited even larger increases in serum CORT $(40.0 \pm 6.8)$.

Unexpectedly, metyrapone-treated animals did not exhibit diminished serum CORT levels relative to controls. Instead, MET animals in Experiment 1 exhibited a mean CORT level of $12.9+3.6 \mu \mathrm{g} / \mathrm{dl}(n=5)$, and bloods taken from the 2 MET + RU animals used in Experiment 2 plus an additional metyrapone-injected animal not used in this study exhibited similar serum CORT levels $(12.1+8.9)$. The range of values observed across all 8 metyraponeinjected animals was large $(2.0-26.2 \mu \mathrm{g} / \mathrm{dl})$, and it is clear that, overall, metyrapone treatment was not an effective means of pharmacological adrenalectomy in these animals.

Student $t$ tests revealed significant differences in CORT titers between the saline- and metyrapone-injected groups, and between the saline- and CORT-injected groups $(p<$ .05 ). Serum glucose levels did not differ across groups and are summarized as follows (glucose, mean millimoles/1 \pm SEM: SAL, $10.65 \pm 0.34, n=6$; INT, $9.68 \pm 0.20$, $n=5$; MET, $10.36 \pm 0.10, n=5$; CORT, $11.18 \pm 1.17$, $n=4)$. These data are shown in Figure 2B. Regression analyses indicated no significant correlation between serum CORT and serum glucose levels.

\section{LTP and LTD: Experiment 1}

LTP and LTD were assessed in several slices from each animal, and group means were based on the total number of stable slices per group (total slices: SAL, $n=16$; INT, $n=17$; MET, $n=14$; CORT, $n=15$ ). All data summarized below are uniformly expressed as mean percent change from the baseline level $( \pm S E M)$, at 30 min posttetanization. Significant differences in both LTP and LTD were observed between conditions (Figure 3 ).

Saline-injected (low serum CORT) and CORT-injected (high serum CORT) animals exhibited only modest increases in population spike amplitude homosynaptically (SAL, 58.6\% $\pm 6.8 \%$; CORT, $57.1 \% \pm 13.8 \%$ ) and decreases heterosynaptically (SAL, $-24.9 \% \pm 4.6 \%$; CORT, $-26.9 \% \pm 9.4 \%$ ) following homosynaptic conditioning. Intact (noninjected) and metyrapone-injected animals (midrange serum CORT levels) exhibited greater LTP and LTD of the spike following tetanization (INT, LTP, $91.7 \% \pm 10.6 \%$, LTD, $-31.7 \% \pm 8.3 \%$; MET, LTP, $102.1 \% \pm 11.4 \%$, LTD, $-55.0 \% \pm 6.3 \%$ ). An analysis of variance (ANOVA) indicated a significant main effect of pharmacological treatment (LTP: $F=5.68, p<.001$; LTD: $F=3.97, p<.002$ ), and post hoc $t$ tests revealed significant differences between the MET and SAL groups ( $p \leq .01$, both LTP and LTD) and the MET and CORT groups ( $p \leq .025$, both LTP and LTD).

EPSP slope measurements confirmed that the pattern of changes observed for population spikes were related to changes in synaptic efficacy. Saline-injected and CORTinjected animals exhibited small percent changes in EPSP slope (SAL, LTP, $5.8 \% \pm 3.0 \%$; LTD, $-1.8 \% \pm 1.9 \%$; CORT, LTP, $1.4 \% \pm 5.5 \%$, LTD, $-2.4 \% \pm 13.8 \%$ ) which were not significantly different between groups. Noninjected and metyrapone-injected animals generally exhibited considerably larger EPSP slope changes both homosynaptically and heterosynaptically than the salineand CORT-injected groups (INT, LTP, $4.4 \% \pm 2.7 \%$; LTD, $-7.3 \% \pm 2.6 \%$; MET, LTP, $17.1 \% \pm 2.3 \%$, LTD, $-8.1 \% \pm 2.5 \%$ ). An ANOVA indicated a significant main effect across conditions for LTP of the EPSP $(F=2.56$, $p<.03$ ), but not for heterosynaptic LTD of the EPSP $(F=0.94, p>.05)$. Post hoc analyses revealed significant differences between the MET and SAL groups $(p=$ $.01)$ and the MET and CORT groups $(p<.03)$ for LTP of the EPSP.

Linear and polynomial regressions were performed to compare mean level of LTP or LTD (both spike and EPSP) for each animal versus serum CORT and serum glucose. Second-order polynomial regressions revealed strong correlations between serum CORT titer and magnitude of LTP or LTD for the homosynaptic spike, heterosynaptic spike, and heterosynaptic EPSP. 


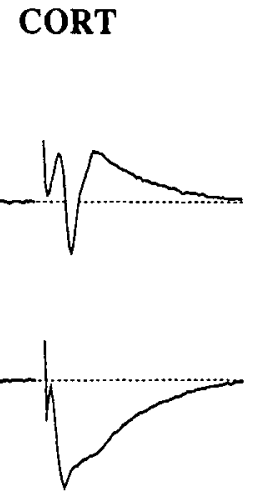

baseline
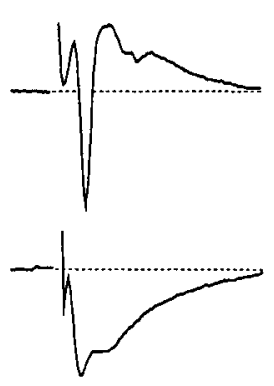

LTP $30 \mathrm{~min}$

\section{METYRAPONE}

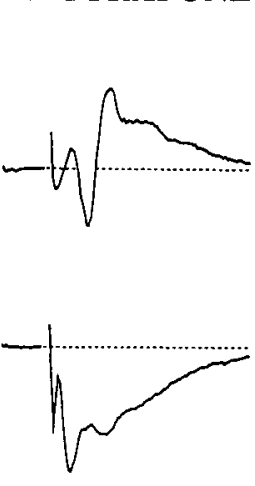

baseline

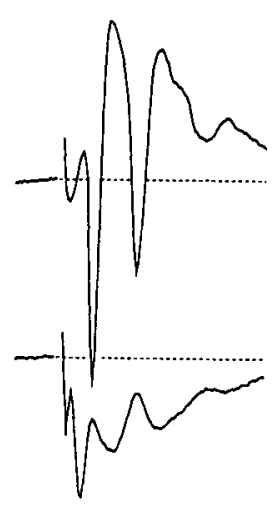

LTP $30 \mathrm{~min}$

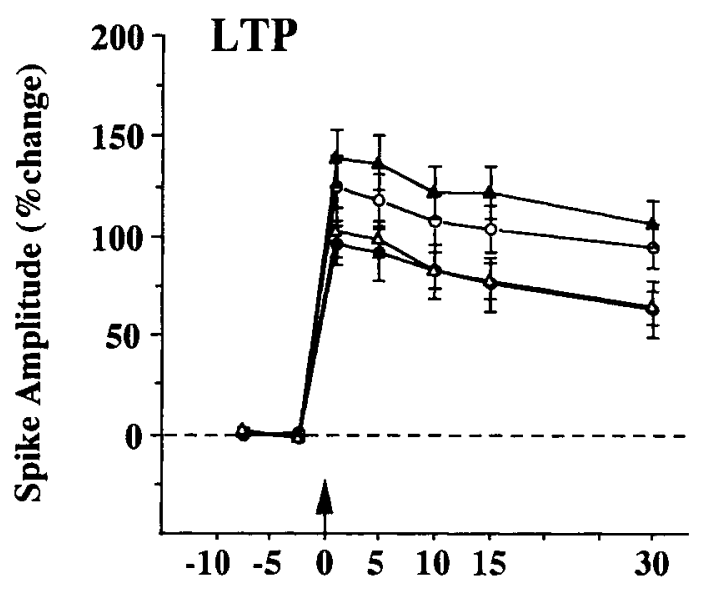

Time (minutes post-tetanization)

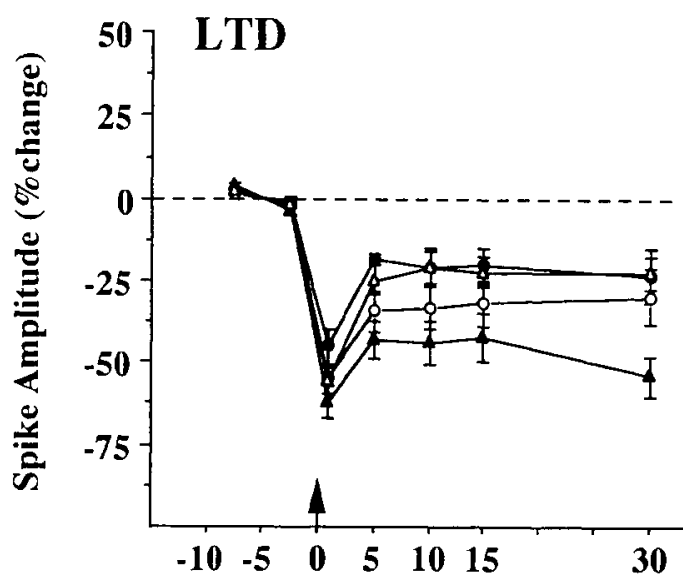

Time (minutes post-tetanization)

Figure 3. Top: Population spikes and field EPSPs recorded from representative slices obtained from CORT-treated and metyrapone-treated animals. Each waveform represents the average of four to five individual, consecutive waveforms during the 1 min prior to tetanization (baseline) or at 30 min posttetanization (long-term potentiation, LTP). Double-spiking following tetanization is routinely observed in picrotoxin (see Method section). Calibration bars apply to all waveforms shown. Bottom: LTP and long-term depression (LTD) for the four groups in Experiment 1. Values shown are population spike amplitude (mean percent change from baseline $\pm S E M$ ). Conditioning stimulation (see Method section) was administered at time $=$ zero (arrow). Dashed line represents baseline levels measured prior to conditioning stimulation. Filled circles, CORT-treated animals; open circles, intact (noninjected) animals; filled triangies, metyrapone-treated animals; open triangles, saline-injected animals.

In addition, regression analyses were performed to establish curves of best fit describing group mean population spike and EPSP slope changes versus group mean serum CORT titers (Figures 4 and 5). Again, second-order polynomial functions were found to provide good descriptions of plasticity versus hormone level for each of the four conditions (spike LTP, $r=0.987$; spike LTD, $r=$ 0.960; EPSP LTP, $r=0.850$; EPSP LTD, $r=0.956$ ). No significant correlations were observed between any of the measures of synaptic plasticity and serum glucose levels.

As shown in Figures 4 and 5, the CORT dependency of both LTP and LTD appears to be well described by inverted-U shaped functions. Accordingly, maximal synaptic plasticity, evidenced by LTP or LTD of either the population spike or EPSP slope, was evident at serum CORT levels of approximately $14-15 \mu \mathrm{g} / \mathrm{dl}$. At lower or higher levels of serum CORT, plasticity (as assessed by any of these four measures) was markedly reduced.

\section{LTP and LTD: Experiment 2}

Additional experiments were conducted in order to assess the possible role of side effects of metyrapone on the modulation of synaptic plasticity seen in Experiment 1, and to determine whether plasticity could also be modulated by in vitro perfusion with the Type II glucocorticoid receptor agonist RU-28362. Animals injected with both metyrapone and CORT ( $n=17$ slices) exhibited reductions in LTP and LTD comparable to those levels seen in animals injected with CORT alone (spike LTP, $47.0 \% \pm$ 

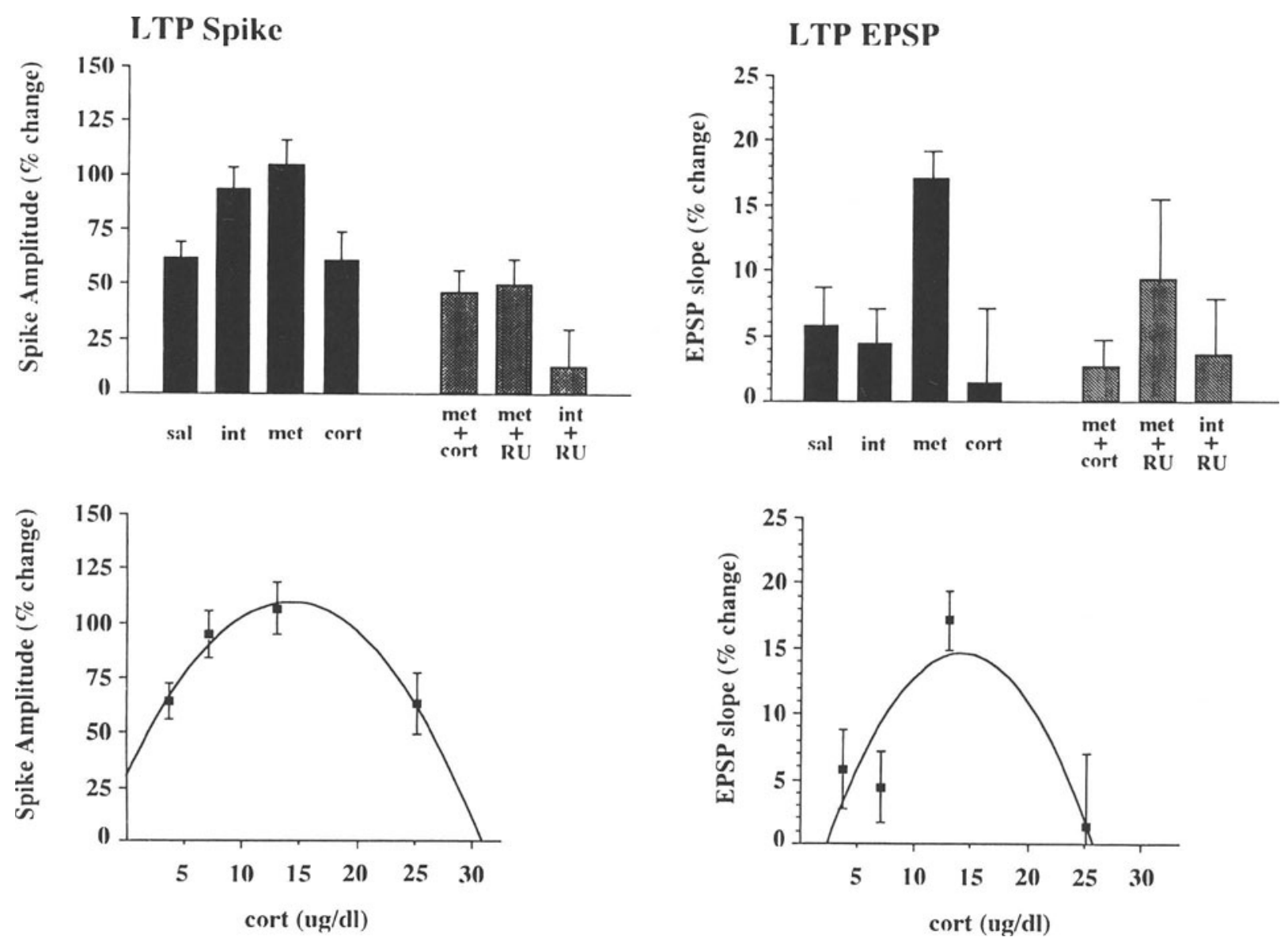

Figure 4. Long-term potentiation (LTP) of the spike and field EPSP for all groups (both Experiments 1 and 2). Bar graphs (top) indicate mean percent change from the baseline level $\pm S E M$; line graphs (below) illustrate mean percent change from baseline $\pm S E M$ for the four groups in Experiment 1 versus mean serum CORT titer for each group. Second-order regressions (lines of best fit) have been superimposed, illustrating inverted-U shaped modulation functions for CORT versus LTP.

$10.5 \%$; spike LTD, $-22.5 \% \pm 4.0 \%$; EPSP LTP, $2.7 \% \pm$ $2.1 \%$; EPSP LTD, $-4.7 \% \pm 1.7 \%$ ). Comparison of the MET + CORT group versus animals injected with metyrapone alone revealed significant differences (unpaired $t$ tests, $p \leq .001$ ) for all measures except LTD of the EPSP.

Slices taken from MET-injected animals and subsequently exposed to RU-28362 ( $n=7$ slices) exhibited significant reductions in LTP $(p<.01)$ and LTD $(p<$ $.001)$ of the spike in comparison with MET-injected animals alone. Similarly, noninjected controls exhibited marked reductions in synaptic plasticity following in vitro perfusion with RU-28362 ( $n=8$ slices). Student $t$ tests revealed significant differences $(p<.01)$ between this group and the MET group on all measures except LTD of the EPSP.

Posttetanic Potentiation and Homosynaptic Depression

In addition to CORT-dependent differences in the induction of LTP and LTD, significant differences were also apparent between groups from 1 to $5 \mathrm{~min}$ posttetanization (Figure 3). Homosynaptic posttetanic potentiation (PTP) and heterosynaptic posttetanic depression (PTD) were reduced in both the SAL and the CORT groups rel- ative to MET-injected animals. An ANOVA indicated a significant treatment effect for both LTP and LTD of the spike, as well as LTP of the EPSP, and post hoc comparisons revealed significant differences between the SAL and MET $(p<.05)$ and CORT and MET $(p<.05)$ conditions. Again, the pattern of change across the four groups conformed to an inverted-U shaped function for CORT level versus degree of synaptic plasticity.

In both Experiments 1 and 2, a number of slices from the low CORT, high CORT, and RU-28362 conditions not only failed to exhibit spike LTP homosynaptically following tetanization, but in some cases even exhibited a degree of lasting homosynaptic depression. No slices from the intermediate CORT conditions (INT and MET) failed to exhibit LTP (Table 1). EPSP slope changes, while relatively small and more variable, showed the same trend.

\section{DISCUSSION}

The results of the present study confirm a prominent role of corticosteroids in the modulation of synaptic plasticity. Using adrenal-intact animals, and thereby avoiding many of the experimental confounds associated with 


\section{LTD Spike}
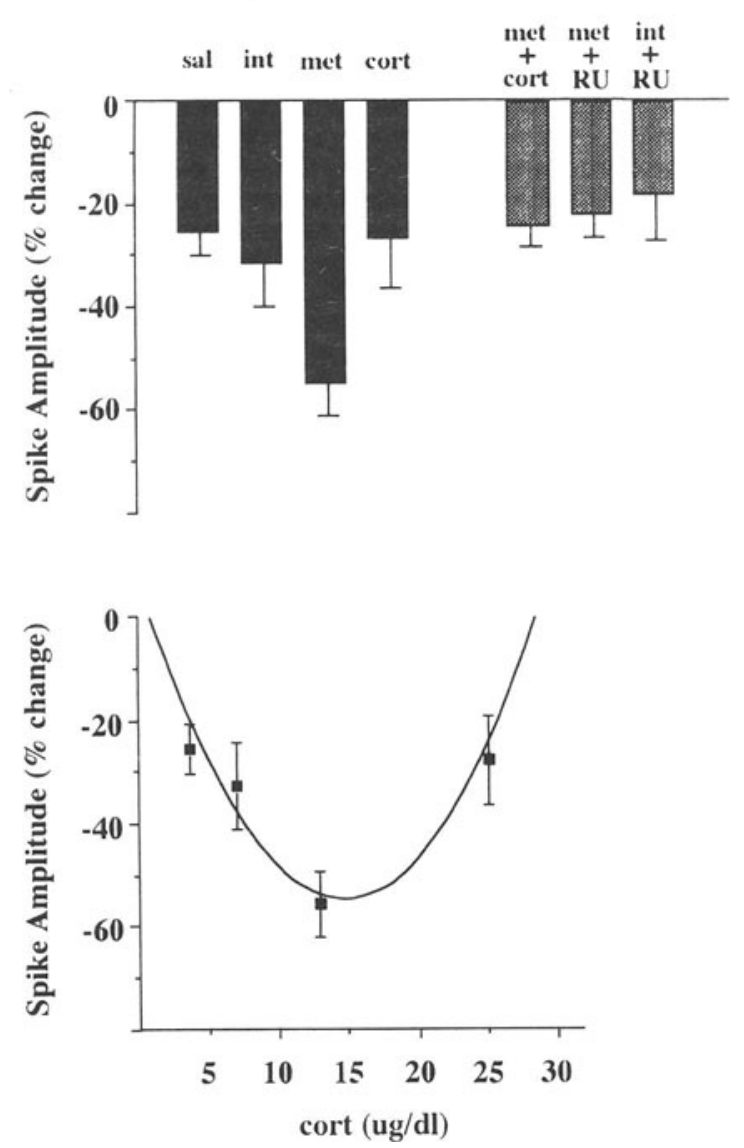

LTD EPSP
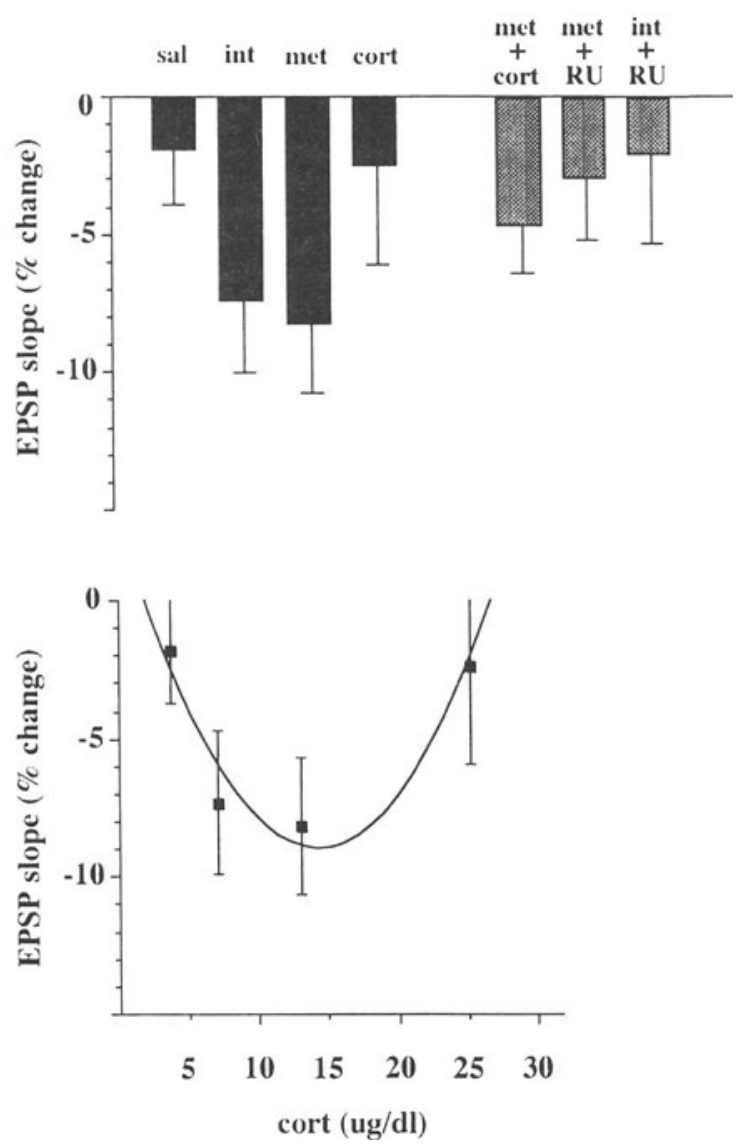

Figure 5. Long-term depression (LTD) of the spike and field EPSP for all groups (both Experiments 1 and 2). All data and figure elements are as in Figure 5.

stress or surgical ADX, we have shown that direct in vivo manipulations of serum CORT can affect both long-term potentiation as well as heterosynaptic long-term depression. Animals with either low or high serum CORT levels exhibited significantly less LTP and LTD than did animals with midrange CORT titers. A consistent invertedU shaped function for CORT versus LTP or LTD was observed in vitro for both the population spike and the field EPSP. The fact that EPSP changes mirrored those occurring for the population spike suggests that corticosteroids modulate plasticity directly at the level of the synapse. The modulation of synaptic plasticity by our in vivo CORT manipulations most likely occurred as a direct result of CSR activation, as opposed to indirect CORT effects. First, selective activation of the Type II glucocorticoid receptor by in vitro application of RU-28362 produced significant reductions in LTP and LTD. Second, although serum glucose levels have been shown to correlate with memory processes in an inverted-U relationship (Gold \& van Buskirk, 1975; Lee et al., 1988), in the present study serum glucose levels did not vary between groups and no relationship was observed between serum
CORT and glucose, or betweeen serum glucose and either LTP or LTD.

These findings are similar to those of recent electrophysiological studies conducted by Bennett et al. (1991) and Diamond, Bennett, et al. (1992) in hippocampal region CA1, and by Pavlides et al. (1992) in the dentate gyrus, in which inverted-U shaped functions were observed for CORT (or specific CSR activation) versus LTP. In the

Table 1

Percent of Slices Either Failing to Exhibit Long-Term Potentiation or Exhibiting Homosynaptic Depression of the Population Spike

\begin{tabular}{|c|c|c|c|c|c|c|c|}
\hline & SAL & INT & MET & CORT & $\begin{array}{c}\text { MET } \\
+ \\
\text { CORT }\end{array}$ & $\begin{array}{c}\text { MET } \\
+ \\
\text { RU }\end{array}$ & $\begin{array}{c}\text { INT } \\
+ \\
\text { RU }\end{array}$ \\
\hline $\begin{array}{l}\text { No LTP } \\
(100-115 \%)\end{array}$ & 7 & 0 & 0 & 14 & 6 & 0 & 0 \\
\hline $\begin{array}{l}\text { Homosynaptic LTD } \\
(<100 \%)\end{array}$ & 0 & 0 & 0 & 14 & 19 & 14 & 44 \\
\hline
\end{tabular}

Note-LTP, long-term potentiation; LTD, long-term depression; SAL, saline-injected controls; INT, noninjected intact controls; MET, injected with metyrapone; CORT, injected with corticosterone; RU, Type II receptor agonist RU-28362, administered in MET or INT animals. 
studies by Bennett et al. (1991) and Diamond, Bennett, et al. (1992) using urethane-anesthetized ADX and intact rats (exhibiting varying levels of urethane-induced CORT secretion), primed burst potentiation (PB-LTP) was reduced in low CORT and high CORT animals relative to animals exhibiting midrange $(9-20 \mu \mathrm{g} / \mathrm{dl})$ serum CORT titers. In addition, primed burst homosynaptic depression (PB-LTD) was routinely observed in animals manifesting very high CORT levels $(50-90 \mu \mathrm{g} / \mathrm{dl})$. Similarly, in a preliminary report by Pavlides et al. (1992), LTP of perforant path-dentate granule cell responses was dependent upon specific CSR activation. In these studies, dentate LTP was reduced in surgically ADX animals and in ADX animals injected with the Type II glucocorticoid receptor agonist RU-28362, whereas ADX animals administered the Type I receptor agonist aldosterone exhibited significantly greater LTP than did animals in either the ADX or the RU conditions (Pavlides et al., 1992).

Our findings confirm and extend previous reports by showing that, in addition to homosynaptic LTP, heterosynaptic LTD in area CA1 also varies with serum CORT level and, presumably, the relative degree of CSR activation. In the present studies, metyrapone-injected animals (midrange CORT levels) consistently exhibited significantly more heterosynaptic LTD in vitro than did either low- or high-CORT subjects. These findings may be of particular interest in light of the fact that many current models of Hebbian-type plasticity now include synaptic depression as an important theoretical component of memory and learning processes (see, e.g., Brown, Kairiss, \& Keenan, 1990). Since LTD has been shown to be a major aspect of functional remodeling of other brain areas, such as the cerebellum (Eckerot \& Kano, 1985; Sakurai, 1990) and visual cortex (Aroniadou \& Teyler, 1991; Artola, Brocher, \& Singer, 1990), it is possible that corticosteroid modulation of synaptic plasticity may account for stressrelated impairments of basic signal processing in these and other brain regions (Daw, Sato, Fox, Carmichael, \& Gingerich, 1991; Fehm-Wolfsdorf, Nagel, \& Fehm, 1991).

While metyrapone has been widely employed as an effective means of reducing serum CORT levels acutely in animals and chronically in humans suffering ardrenocortical hypersecretion (e.g., Cushing's syndrome; see Haynes, 1990), the blockade of CORT biosynthesis was not complete in the present studies. Metyrapone-injected animals actually exhibited higher CORT titers than did either the saline-injected or the uninjected controls. This result, while unexpected, proved fortuitous in that the robust expression of LTP and LTD associated with midrange CORT titers may have gone unobserved had the drug fully reduced serum CORT levels in this group of animals. The fact that the drug treatment was ineffective remains without explanation. We administered metyrapone in sufficient doses (Murison et al., 1989; Stein \& Sapolsky, 1988) subcutaneously to ensure a steady release and presumably constant inhibition of CORT synthesis for the 2 days prior to sacrifice. However, chronic metyrapone treatment has been associated with lasting elevations of adrenocor- ticotropic hormone (ACTH) apparently because of reduced negative feedback by CORT on the hypothalamicpituitary axis (Plotsky \& Sawchenko, 1987; Rose, Turner, Ray, \& Rawashdeh, 1988), and it may be that increased ACTH stimulation of the adrenal cortex is sufficient to counteract the inhibition of CORT synthesis by the drug. Thus, although metyrapone may be clinically effective in cases of adrenal hypersecretion, it does not appear to be fully effective in animals with normal (i.e., unperturbed) hypothalamic-pituitary-adrenal axes (see, e.g., Freo, Holloway, Kalogeras, Rapoport, \& Soncrant, 1992; Murison et al., 1989). These findings may be of relevance in future investigations of pharmacologically adrenalectomized animals.

It is possible that group differences in ACTH levels account for the relative differences in LTP and LTD observed in this study. Although serum ACTH was not assessed in these studies, given the fact that in vitro administration of RU-28362 to slices taken from METinjected animals and noninjected controls resulted in marked reductions in LTP and LTD, we believe that the modulation of synaptic plasticity observed here is due to activation of Type I and/or Type II glucocorticoid receptors by CORT (or RU-28362) alone as opposed to any modulatory influences of ACTH. The effect of RU-28362 observed here is consistent with preliminary reports demonstrating (1) a dose-dependent suppression of PB-LTP by the Type II receptor agonist dexamethasone in urethaneanesthetized ADX rats (presumably exhibiting high $\mathrm{ACTH}$ ) in vivo (Diamond, Branch, Bennett, Fleshner, \& Rose, 1992), and (2) a Type II receptor dependent suppression of LTP in the dentate gyrus of ADX rats (Pavlides et al., 1992). We also considered the possibility that the robust expression of LTP and LTD seen in the METinjected group was due to a side effect of the metyrapone itself. However, animals injected with both MET and CORT exhibited significant reductions in both forms of synaptic plasticity, suggesting either that MET does not exert non-CORT related modulatory effects on LTP/LTD, or that the co-administration of CORT is sufficient to override or reverse this modulation.

Corticosteroid receptor up- and down-regulation have been demonstrated following various long-term manipulations (Reul et al., 1987), but it does not seem likely that the group differences seen in this study are due to individual differences in receptor capacity. In general, CSR up-regulation in young adult rats does not become apparent before 3-7 days of ADX (Eldridge, Fleenor, Kerr, Campbell, \& Landfield, 1989), and significant downregulation of CSRs has not been observed earlier than 1 week or longer following exogenous CORT administration (Meaney, Sapolsky, \& McEwen, 1985) or chronic stress (Eldridge, Brodish, et al., 1989). Our manipulations took place over a period of 2 days (sacrifice on the morning of the 3rd day), and presumably sufficient time had not elapsed for MR or GR autoregulation.

The finding that RU-28362 produced reductions in LTP/LTD suggests that Type I receptor occupancy facili- 
tates synaptic plasticity, but that Type II receptor occupancy is inhibitory. This idea is consistent with the findings of Joels and de Kloet that Type I and Type II receptor activation produces opposite effects on cell excitability. Type I receptor activation produces increases in cell excitability, as is evidenced by measures of spike accomodation and suppression of 5-HT induced hyperpolarizations (Joels \& de Kloet, 1990; Joels, Hesen, \& de Kloet, 1991), whereas Type II activation produces consistent decreases in cell excitability, which are apparently due to prolongation of the $\mathrm{Ca}^{2+}$-dependent afterhyperpolarization $\left(\mathrm{AHP}_{\mathrm{Ca}}\right.$; Joels \& de Kloet, 1989, 1990; Kerr, Campbell, Hao, \& Landfield, 1989).

Specific mechanisms underlying the modulation of LTP/LTD by CORT have not been identified. However, because of the fact that the Type I and Type II receptors exert opposing actions on CA1 AHPs, Bennett et al. (1991) and Diamond, Bennett, et al. (1992) have suggested that the group differences in PB-LTP that they observed may be related to differences in the effectiveness of the primed burst conditioning. That is, CORT enhancement of the $\mathrm{AHP}_{\mathrm{Ca}_{\mathrm{a}}}$ that follows the priming pulse may have shunted or offset the depolarization normally produced during the high-frequency burst delivered afterward. The same reasoning may also apply in our use of theta-burst conditioning in the present study. Thus, by differentially regulating cell excitability, CORT could be indirectly affecting the voltage-dependent activation of NMDA receptor/channels, which are known to be important for both LTP and heterosynaptic LTD (Abraham \& Wickens, 1991; Christie \& Abraham, 1992). As selective Type II CSR activation has been shown to modulate $\mathrm{Ca}^{2+}$ influx through both $\mathrm{N}$ - and L-type $\mathrm{Ca}^{2+}$ channels (Kerr, Campbell, Thibault, \& Landfield, 1992), the hypothesis that corticosteroids modulate LTP and LTD through a $\mathrm{Ca}^{2+}$-dependent process seems attractive and certainly merits further attention. For example, if that is true, then it is possible that the application of specific $\mathrm{Ca}^{2+}$ channel blockers might prevent CORT-related reductions in synaptic plasticity.

Regardless of the precise mechanisms underlying these effects, the present findings support the contention that glucocorticoids alone can modulate hippocampal synaptic plasticity, and that this modulation may depend on the degree of Type I or Type II CSR activation. Our data are consistent with recent reports demonstrating an inverted-U shaped function for CORT versus LTP in the dentate gyrus (Pavlides et al., 1992) and area CA1 (Bennett et al., 1991; Diamond, Bennett, et al., 1992), and they further demonstrate a similar pattern of corticosteroid modulation of heterosynaptic LTD. Collectively, these findings may be relevant to previous reports of LTP variation during the circadian rhythm (Dana \& Martinez, 1984) or following ADX versus acute stress (Shors et al., 1990a), and may further relate to recent behavioral evidence of differential roles of the hippocampal MR and GR receptor systems in memory and learning (Bodnoff, Humphreys,
Rose, \& Meaney, 1992; Oitzl \& de Kloet, 1992a, 1992b). When considered together with the inverted- $U$ shaped learning functions previously demonstrated for peripheral epinephrine (Gold \& van Buskirk, 1975) and central glucose (Lee et al., 1988), the relatively slow and lingering actions of corticosteroids may well act in concert with the more immediate adrenal catecholamines to facilitate the acquisition and consolidation of information in a stressful environment.

\section{REFERENCES}

Abraham, W. C., \& Wickens, J. R. (1991). Heterosynaptic long-term depression is facilitated by blockade of inhibition in area CA1 of the hippocampus. Brain Research, 546, 336-340.

ARONIADOU, V. A., \& TEYLER, T. J. (1991). The role of NMDA receptors in long-term potentiation (LTP) and depression (LTD) in rat visual cortex. Brain Research, 562, 136-143.

Artola, A., Brocher, S., \& Singer, W. (1990). Different voltagedependent thresholds for inducing long-term depression and long-term potentiation in slices of rat visual cortex. Nature, 347, 69-72.

AXELRoD, J., \& ReISINE, T. D. (1984). Stress hormones: The interaction and regulation. Science, 224, 452-459.

Bennett, M. C., Diamond, D. M., Fleshner, M., \& Rose, G. M. (1991). Serum corticosterone level predicts the magnitude of hippocampal primed burst potentiation and depression in urethaneanesthetized rats. Psychobiology, 19, 301-307.

Bodnoff, S. R., Humphreys, A., Rose, G. M., \& Meaney, M. J. (1992). Effects of corticosterone and stress on spatial learning, hippocampal plasticity, and neuron loss. Society for Neuroscience Abstracts, $18,534$.

Brown, T. H., Kairiss, E. W., \& Keenan, C. L. (1990). Hebbian synapses: Biophysical mechanisms and algorithms. Annual Review of Neuroscience, 13, 475-511.

Christie, B. R., \& Abraham, W. C. (1992). NMDA-dependent heterosynaptic long-term depression in the dentate gyrus of anaesthetized rats. Synapse, 10, 1-6.

Dallman, M. F., Akana, S. F., Jacobson, L., levin, N., Cascio, C. S., Shinsako, J. (1987). Characterization of corticosterone feedback regulation of ACTH secretion. In W. F. Ganong, M. F. Dallman, J. L. Roberts (Eds.), The hypothalamic-pituitary-adrenal axis revisited (Annals of the New York Academy of Sciences, Vol. 512, pp. 402414). New York: New York Academy of Sciences.

Dana, R. C., Gerren, A., Sternberg, D. B., Martinez, J. L., Hall, J., Stansbury, N. A., \& Weinberger, N. M. (1982). Long-term potentiation is impaired by adrenalectomy and restored by corticosterone. Society for Neuroscience Abstracts, 8, 316.

Dana, R. C., \& Martinez, J. L. (1984). Effect of adrenalectomy on the circadian thythm of LTP. Brain Research, 308, 392-395.

Daw, N. W., Sato, H., Fox, K., Carmichael, T., \& Gingerich, R. (1991). Cortisol reduces plasticity in the kitten visual cortex. Journal of Neurobiology, 22, 158-168.

de Kloet, E. R., Ratka, A., Reul, J. M. H. M., Sutanto, W., \& VAN EEKELEN, J. A. M. (1987). Corticosteroid receptor types in brain: regulation and putative function. In In W. F. Ganong, M. F. Dallman, J. L. Roberts (Eds.), The hypothalamic-pituitary-adrenal axis revisited (Annals of the New York Academy of Sciences, Vol. 512, pp. 351361). New York: New York Academy of Sciences.

DE WIED, D. (1989). Neuroendocrine aspects of learning and memory processes. News in Physiological Sciences, 4, 32-38.

Diamond, D. M., Bennett, M. C., Engstrom, D. A., Fleshner, M., \& Rose, G. M. (1989). Adrenalectomy reduces the threshold for hippocampal primed burst potentiation in the anesthetized rat. Brain Research, 492, 356-360.

Diamond, D. M., Bennett, M. C., Fleshner, M., \& Rose, G. M. (1992). Inverted-U relationship between the level of peripheral corti- 
costerone and the magnitude of hippocampal primed burst potentiation. Hippocampus, 2, 421-430.

Diamond, D. M., Bennett, M. C., Stevens, K. E., Wilson, R. L., \& Rose, G. M. (1990). Exposure to a novel environment interferes with the induction of hippocampal primed burst potentiation in the behaving rat. Psychobiology, 18, 273-281.

Diamond, D. M., Branch, B., Bennett, M. C., Fleshner, M., \& Rose, G. M. (1992). Dexamethasone blocks the induction of hippocampal primed burst potentiation. Society for Neuroscience Abstracts, $18,1348$.

ECKEROT, C.-F., \& KaNo, M. (1985). Long-term depression of parallel fibre synapses following stimulation of climbing fibres. Brain Research, 342, 357-360.

Eldridge, J. C., Brodish, A., Klute, T. E., \& Landfield, P. W. (1989). Apparent age-related resistance of type II hippocampal corticosteroid receptors to down-regulation during chronic escape training. Journal of Neuroscience, 9, 3237-3242.

Eldridge, J. C., Fleenor, D. G., Kerr, D. S., Campbell, L. W., \& LANDFIELD, P. W. (1989). Impaired up-regulation of type II corticosteroid receptors in hippocampus of aged rats. Brain Research, 478, 248-256.

Fehm-Wolfsdorf, G., Nagel, D., \& Fehm, H. L. (1991). Stress induced cortisol secretion influences information processing in man. Society for Neuroscience Abstracts, 17, 1409.

Foy, M. R., Stanton, M. E., Levine, S., \& Thompson, R. F. (1987). Behavioral stress impairs long-term potentiation in rodent hippocampus. Behavioral \& Neural Biology, 48, 138-149.

Freo, U., Holloway, H. W., Kalogeras, K., Rapoport, S. I., \& SONCRANT, T. T.(1992). Adrenalectomy or metyrapone-pretreatment abolishes cerebral metabolic responses to the serotonin agonist 1-(2,5dimethoxy-4-iodophenyl)-2-aminopropane (DOI) in the hippocampus. Brain Research, 586, 256-264.

Fuxe, K., Wikstrom, A.-C., Okret, S., Agnati, L. F., Harfstrand, A., Yu, Z. Y., Granhol.m, L., Zoli, M., Vale, W., \& GustafsSon, J.-A. (1985). Mapping of glucocorticoid receptor immunoreactive neurons in the rat tel- and diencephalon using a monoclonal antibody against rat liver glucocorticoid receptor. Endocrinology, 117, 1803-1812.

GoLD, P. E. (1986). Glucose modulation of memory storage. Behavioral \& Neural Biology, 45, 342-349.

Gold, P. E., Delanoy, R. L., \& Merrin, J. (1984). Modulation of long-term potentiation by peripherally administered amphetamine and epinephrine. Brain Research, 305, 103-107.

GoLD, P. E., \& VAN BuskIRK, R. (1975). Facilitation of time-dependent memory processes with posttrial epinephrine injections. Behavioral Biology, 13, 145-153.

GoLD, P. E., \& VAN Buskirk, R. (1976). Enhancement and impairment of memory processes with post-trial injections of adrenocorticotropic hormone. Behavioral Biology, 16, 387-400.

HAYNES, R. C. (1990). Adrenocorticotropic hormone: Adrenocortical steroids and their synthetic analogs; inhibitors of the synthesis and actions of adrenocortical hormones. In A. G. Goodman, T. W. Rall, A. S. Nies, \& P. Taylor (Eds.), Goodman and Gilman's The pharmacological basis of therapeutics (8th ed., pp. 1431-1462). Elmsford, NY: Pergamon Press.

JoELS, M., \& DE KLOET, E. R. (1989). Effects of glucocorticoids and norepinephrine in the hippocampus. Science, 245, 1502-1505.

Joels, M., \& DE KLOET, E. R. (1990). Mineralocorticoid receptormediated changes in membrane properties of rat $\mathrm{CA} 1$ pyramidal neurons in vitro. Proceedings of the National Academy of Sciences, 87, 4495-4498.

JoELS, M., \& DE KLOET, E. R. (1992a). Control of neuronal excitability by corticosteroid hormones. Trends in Neuroscience, 15, 25-30.

JoEls, M., \& DE KLOET, E. R. (1992b). Coordinative mineralocorticoid and glucocorticoid receptor-mediated control of responses to serotonin in rat hippocampus. Neuroendocrinology, 55, 344-350.

Joels, M., Hesen, W., \& DE KLOET, E. R. (1991). Mineralocorticoid hormones suppress serotonin-induced hyperpolarization of rat hippocampal CA1 neurons. Journal of Neuroscience, 11, 2288-2294.
KerR, D. S., \& ABraham, W. C. (1993). A comparison of associative and non-associative conditioning procedures in the induction of LTD in CA1 of the hippocampus. Synapse, 14, 305-313.

Kerr, D. S., Campbell, L. W., Hao, S-Y., \& Landfield, P. W. (1989). Corticosteroid modulation of hippocampal potentials: increased effect with aging. Science, 245, 1505-1509.

Kerr, D. S., Campbell, L. W., Thibault, O., \& Landfield, P. W. (1992). Hippocampal glucocorticoid receptor activation enhances voltage-dependent calcium conductance: Relevance to brain aging. Proceedings of the National Academy of Sciences, 89, 8527-8531.

Kerr, D. S., Huggett, A. M., \& Abraham, W. C. (1993). Glucocorticoid modulation of synaptic plasticity in area CA1 of the hippocampus. International Journal of Neuroscience, 71, 118-119.

LeE, M. K., Graham, S. N., \& Gold, P. E. (1988). Memory enhancement with posttraining intraventricular glucose injections in rats. $B e$ havioral Neuroscience, 102, 591-595.

Meaney, M. J., Sapolsky, R. M., \& McEwen, B. S. (1985). The development of the glucocorticoid receptor system in the rat limbic brain: I. Ontogeny and autoregulation. Developmental Brain Research, 18, 159-164.

McEwen, B. S., WALlach, G., \& Magnus, C. (1974). Corticosterone binding to hippocampus: Immediate and delayed influence of the absence of adrenal secretion. Brain Research, 70, 321-326.

McEwen, B. S., Weiss, J. M., \& SChWARTZ, C. S. (1969). Uptake of corticosterone by rat brain and its concentration by certain limbic structures. Brain Research, 16, 227-241.

Murison, R., Overmeier, J. B., Hellhammer, D. H., \& CarMONA, M. (1989). Hypothalamo-pituitary-adrenal manipulations and stress ulcerations in rats. Psychoneuroendocrinology, 14, 331-338.

Nowicky, A. V., Vardaris, R. M., \& TeYler, T. J. (1983). Corticosterone and long-term potentiation in the hippocampus. Society for Neuroscience Abstracts, 9, 1211.

ODIo, M., \& BRODISH, A. (1989). Age-related adaptation of pituitaryadrenocortical responses to stress. Neuroendocrinology, 49, 382-388.

OITZL, M. S., \& DE KLOET, E. R. (1992a). Corticosterone modulates exploration via central mineralocorticoid receptors. Society for Neuro science Abstracts, 18, 718 .

OITZL, M. S., \& DE KLOET, E. R. (1992b). Selective corticosteroid antagonists modulate specific aspects of spatial orientation learning. Behavioral Neuroscience, 106, 62-71.

Pavlides, C., Watanabe, Y., Margarinos, A. M., \& McEwen, B. S. (1992). Effects of glucocorticoid Type I and Type II agonists on hippocampal long-term potentiation. Society for Neuroscience Abstracts, $18,343$.

Pavlides, C., Watanabe, Y., \& McEwen, B. S. (1993). Effects of glucocorticoids on hippocampal long-term potentiation. Hippocampus, 3, 183-192.

Plotsky, P. M., \& Sawchenko, P. E. (1987). Hypophysial-portal plasma levels, median eminence content, and immunohistochemical staining of corticotropin-releasing factor, arginine vasopressin, and oxytocin after pharmacological adrenalectomy. Endocrinology, 120, 1361-1369.

ReUl, J. M. H. M., \& DE KLOET, E. R. (1986). Anatomical resolution of two types of corticosterone receptor sites in rat brain with in vitro autoradiography and computerized image analysis. Joumal of Steroid Biochemistry, 24, 269-272.

Reul, J. M. H. M., Van den Bosch, F. R., \& de Kloet, E. R. (1987). Differential response of Type I and Type II corticosteroid receptors to changes in plasma steroid level and circadian rhythmicity. Neuroendocrinology, 45, 407-412.

Rose, J. C., Turner, C. S., Ray, D., \& Rawashdeh, N. (1988). Evidence that cortisol inhibits basal adrenocorticotropin secretion in the sheep fetus by 0.70 gestation. Endocrinology, 123, 1307-1313.

SAKURA, M. (1990). Calcium is an intracellular mediator of the climbing fiber in induction of cerebellar long-term depression. Proceedings of the National Academy of Sciences, 87, 3383-3385.

Sapolsky, R. M., Krey, L. C., \& McEwen, B. S. (1985). Prolonged glucocorticoid exposure reduces hippocampal neuron number: Implications for aging. Journal of Neuroscience, 5, 1222-1227. 
SCHLATtER, L. K., \& DoKas, L. A. (1989). Receptor specificity of a glucocorticoid- and stress-induced hippocampal protein. Journal of Neuroscience, 9, 1134-1140.

Shors, T. J., Levine, S., \& Thompson, R. F. (1988). Effect of stress and adrenalectomy on long-term potentiation in rat hippocampus. Society for Neuroscience Abstracts, 14, 443.

Shors, T. J., Levine, S., \& Thompson, R. F. (1990a). Effect of adrenalectomy and demedullation on the stress-induced impairment of long-term potentiation. Neuroendocrinology, 51, 70-75.

Shors, T. J., LeVINE, S., \& THOMPSON, R. F. (1990b). Opioid antagonist eliminates the stress-induced impairment of long-term potentiation (LTP). Brain Research, 506, 316-318.
Shors, T. J., Seib, T. B., Levine, S., \& Thompson, R. F. (1989). Inescapable versus escapable shock modulates long-term potentiation in the rat hippocampus. Science, 244, 224-226.

Stein, B. A., \& SAPOLSKY, R. M. (1988). Chemical adrenalectomy reduces hippocampal damage induced by kainic acid. Brain Research, 473, 175-180.

(Manuscript received May 3, 1993;

revision accepted for publication November 5,1993 .) 